\title{
Bargaining and Fixed Price Offers: How Online Intermediaries are Changing New Car Transactions
}

\author{
MICHAEL A. ARNOLD \\ Department of Economics, University of Delaware \\ THIERRY PÉNARD * \\ CREM, University of Rennes 1
}

\begin{abstract}
This paper develops a model of oligopolistic price competition to analyze the impact of online intermediaries such as Autobytel.com on the price setting process in the automobile market. The roles of dealer search costs, the fraction of buyers using the intermediary, the value of the item being sold, and heterogeneity in buyer bargaining abilities are explored. The model provides theoretical insights relevant to the empirical literature addressing the role that intermediaries like Autobytel play in online markets. For example, we present conditions under which the price offered through the intermediary is either higher or lower than offline (bargained) prices.
\end{abstract}

\section{Introduction}

The rapidly expanding diffusion of the Internet into everyday life has altered traditional interactions between buyers and sellers. The Internet provides many online buying services that expand the reach of sellers, and reduce search costs for buyers by providing a wealth of product information, identifying sellers of the product and comparing prices offered by several online retailers. A large literature has empirically examined the impact of Internet retailers on price competition and price dispersion in markets characterized by posted prices. ${ }^{1}$ An issue that has received much less attention is the impact of the Internet on the price setting process. The presence of an intermediary or middleman can alter the way in

\footnotetext{
* Contact Author. thierry.penard@univ-rennes1.fr This research was supported by the Alfred Lerner College of Business and Economics Summer Research Grant program. We thank two anonymous referees, Eric Brousseau and participants at the Conference on The Economics of E-Intermediation (Paris, June 2005) for helpful comments.

${ }^{1}$ Examples include Bailey (1998), Brynjolfsson and Smith (2000, 2001); Clay, Krishnan and Wolff (2001), Arnold and Saliba (2002), Baye, Morgan and Scholten, (2006) or Penard and Larribeau (2004). These papers, which have focused primarily on the markets for books, CD's, and consumer electronics, all find evidence of persistent price dispersion between online sellers of a homogeneous product.
} 
which prices are established ${ }^{2}$ and the Internet has made such intermediaries increasingly common. For example, eBay enables buyers and sellers to exchange new or used products through an auction-style mechanism. At the end of 2006, 222 million users were registered on eBay and in 2006, the value of trades on the eBay marketplace exceeded 52.4 billion dollars. Priceline.com is another example of an infomediary that has introduced a buyer bidding process into markets traditionally characterized by posted prices by enabling customers to name their own price for an airline flight, rental car, or hotel room. ${ }^{3}$

Our article focuses on referral intermediaries like Autobytel in the retail market for automobiles and seeks to understand how these intermediaries influence the price setting process. A key feature of traditional automobile markets is that transaction prices are typically negotiated between the buyer and seller. ${ }^{4}$ Because buyers often dislike bargaining, the automobile market represents an opportunity for online intermediaries. In particular, an online intermediary can facilitate the simultaneous use of multiple pricing mechanisms by a given dealer. Autobytel.com enables automobile dealers to offer a posted price to buyers who contact the dealer through Autobytel.com and to bargain with buyers who contact the dealer through other channels. In addition to accessing detailed product information (such as standard features and options, safety ratings, and dealer invoice pricing), a prospective buyer can use Autobytel to request a non-negotiable, fixed-price offer on a specific automobile. This request is transmitted to the nearest dealer with which Autobytel has a geographically exclusive agreement (in exchange for a subscription fee paid by the dealer to Autobytel). The dealer commits to respond to buyer requests within 48 hours and to offer the buyer a posted price equivalent to the best price that a skilled bargainer could negotiate directly at the dealership.

Although the automobile industry is somewhat unique as a retail channel in which transaction prices are typically established through bargaining, the question of how the internet has impacted the price setting process is of significant interest because of the magnitude of this market. According to the National Automobile Dealers Association, new car dealerships in the United States sold over 16.9 million new vehicles in 2005 at a total value exceeding $\$ 481$ billion. This accounts for approximately 15.8 percent of the value of total retail trade in the United States in 2005. Evidence of the role that online intermediaries play in this market is provided by Scott Morton et al (2001) who find that from a sample of nearly 325 thousand new automobile sales in California in 1999, 2.94 percent were purchased by buyers who requested a price quote through Autobytel. Consumer surveys conducted by J.D. Power and Associates also indicate the increasing role of the Internet in new automobile purchases. The J.D. Power 2006 New Autoshopper.com Study reports that 67.5 percent of new automobile buyers used the

\footnotetext{
${ }^{2}$ For example, Biglaiser (1993) shows that both the average price and the quality of goods tend to be higher when goods are sold through an intermediary instead of through direct bargaining. See also Wang (1995), Arnold and Lippman (1993), Spier (1991) or Bester (1994) about the sellers's choice between posted prices and bargaining.

${ }^{3}$ The bid can be accepted or refused by the sellers referred by Priceline. If the bid is refused, then the customer has the chance to make another bid but only if he modifies the terms of his request (such as the location or the star level of the hotel). Fay (2004) considers the impact of a bidder's ability to submit repeat bids on Priceline.com's profit and shows that profit is higher if bidders can be credibly prevented from submitting repeat bids. Ding et al (2005) demonstrate that bids may be influenced by the emotional response of bidders based on whether bids submitted in the past were accepted or rejected.

${ }^{4}$ The notable exception is Saturn which sells cars at the non-negotiable sticker price. Saturn has a wellknown reputation for adhering to its "no-haggling" policy.
} 
Internet to research their purchase, up from 54 percent in 2000 (the approximate time period of the Scott Morton et al data). Viswanathan et al (2005) shed some light on the type of information acquired online by car buyers (either price information or product information). They find that buyers who primarily search web sites that provide price information (but not necessarily a price quote) pay a lower price, on average, than buyers who purchase the same car without acquiring this information, while buyers who primarily search for product information pay an above average price. But their empirical study does not provide direct evidence on the role of referral intermediaries.

To investigate the effects of a referral system like Autobytel on the price setting process, we develop a model of oligopolistic price competition in which one dealership has an exclusive contract with a referral infomediary. ${ }^{5}$ Consumers are differentiated by their ability to negotiate (as either strong or weak bargainers) and by whether or not they use the referral service. Buyers who do not obtain a price quote from the referral service bargain directly with a local dealer. Buyers who use the referral system obtain a fixed price offer from the referred dealer and then decide to either purchase at that fixed price or to reject the offer and bargain with a local dealer. Our objective is to theoretically investigate how the intermediary influences equilibrium prices and how this depends upon market parameters such as the percentage of buyers who use the intermediary, the difference in buyer bargaining abilities, the rate at which buyers arrive in the market and the seller's cost of attracting buyers.

Our framework is related to the broader literature investigating online intermediaries. This literature has generally focused on environments in which sellers post prices in all channels - both to buyers encountered directly and to buyers encountered through the intermediary. For example, Chen et al (2002) analyze the impact of a referral infomediary in a market with two retailers that compete for two types of buyers: loyal buyers who only observe the price announced by one dealer and shoppers who compare prices and buy from the lowest price dealer. As in our model, the infomediary gives the referred dealer access to a fraction of the competing dealer's loyal customers and also enables the referred dealer to price discriminate between loyal buyers and shoppers. Chen et al find that the profits of the referral infomediary can decline when its reach becomes too large. As more and more buyers use the referral service, competition between dealers increases and drives their profits to zero. Their second finding is that the infomediary prefers to offer geographically exclusive contracts. Ghose et al (2002) extend this model by adding a manufacturer that can provide non-exclusive referral services. They emphasize that direct (face-to-face) selling enables sellers to discover each buyer's willingness-to-pay and to price discriminate, whereas online selling makes price discrimination more difficult. In the online retail channel, the seller has less direct information on the characteristics of the buyer and is unable to infer the buyer's willingness-to-pay. This forces the dealer to quote a single price, whereas with offline buyers the seller can set different prices depending on the observed willingness-to-pay of each buyer.

As in the models of Chen et al and Ghose et al, the intermediary in our model increases the proportion of customers with whom the referred dealer interacts and dealers are able to price discriminate between buyers encountered directly at the dealership. In contrast to their models, we allow for the possibility of more than two dealers and we do not assume

\footnotetext{
${ }^{5}$ The intermediary offers an exclusive contract with a single dealer to prevent severe (Bertrand) price competition for referred buyers which would result if the intermediary referred a buyer to multiple dealers. Such price competition would render the intermediary worthless.
} 
that some buyers are fully informed. ${ }^{6}$ As a result, buyers encountered through the referral system may be quoted a price which exceeds the average price paid by buyers who bargain with the dealer directly. In particular, our framework highlights the importance of heterogeneity in buyer bargaining ability in determining how the intermediary impacts the price setting process. The intermediary provides buyers with lower prices (on average) if the difference in buyer bargaining abilities is sufficiently small. If the difference in buyer bargaining abilities is large, then the price quoted by the intermediary is equivalent to the price that the weakest bargainer would negotiate with his or her local dealer. However, weak bargainers still have an incentive to use the intermediary because by doing so, they avoid having to negotiate a price with a dealer. Use of the intermediary also enables the buyer to commit to his or her preferred car and option package and to obtain a fixed price offer on that car. The alternative of negotiating with the dealer is likely to be complicated by haggling over multiple attributes including price, option packages and features (such as car color), and financing. If the buyer does not perceive that a better deal will be obtained by negotiation with a local dealer, then the fixed price offered through the referral system will be accepted.

Comparative statics analysis predicts that the price offered by the intermediary will be lower than the average negotiated price if either the cost to dealers of attracting buyers or the number of dealers in the market is sufficiently large. Under such conditions, the referred firm offers a more competitive price through the intermediary in order to fully take advantage of the increased market reach offered by the intermediary. In addition, the referral system is not viable under certain market conditions which induce significant price reductions as non-referred dealers and the referred dealer compete for buyers who use the referral system. If the value of the item is large (so the surplus over which the buyer and seller are bargaining is large) and the difference in buyer bargaining abilities is small, then the benefit of the increased reach offered by the intermediary is more than offset by the reduction in equilibrium prices caused by dealers competing to attract buyers who use the referral system. In this case, no dealer will contract with the intermediary.

Our paper is organized as follows. Section 2 presents the assumptions of the model and establishes basic theoretical propositions. Section 3 extends the basic model to allow nonreferred dealers to advertise a lower price in order to compete with the referred dealer for buyers who utilize the infomediary. Section 4 offers concluding remarks.

\section{The model}

We consider a simple market with $N$ firms that sell a homogeneous good to consumers who arrive in the market according to a Poisson process with rate $\lambda$. Each firm incurs a search cost $c$ per unit of time. This cost can be thought of as the cost of operating the dealer's business or as an advertising cost. Exactly one of the $N$ firms, which we label firm $A$, has an exclusive relationship with an information intermediary or referral service. With probability $\phi$, a buyer entering the market requests a price offer through the intermediary and is referred directly to firm $A$. Firm $A$ quotes this buyer a price $r$. With

\footnotetext{
${ }^{6}$ The presence of "shoppers" who are fully informed of all prices results in equilibrium mixed pricing strategies as in Varian (1980). When considering the case of offline markets, particularly for automobiles where search and bargaining costs required to obtain a price quote can be quite high, the assumption that some buyers are "shoppers" who receive price quotes from all sellers is not applicable.
} 
probability $1-\phi$, a buyer entering the market does not use the intermediary and is allocated randomly to one of the $N$ firms. In this case, the buyer negotiates with the dealer and pays a price that depends on his or her ability to negotiate.

Buyers all have the same fixed reservation value $v$. This valuation may be thought of as the manufacturer's suggested retail price (MSRP). This interpretation implies that if a dealer attempts to negotiate a price which exceeds the MSRP, the buyer will always reject this dealer and purchase from another dealer at a price no greater than the MSRP. ${ }^{7}$ While the MSRP establishes one potential upper bound on the price any buyer will pay, individual sellers also have the ability to commit to a lower upper bound by advertising a price $p$ less than the MSRP. The buyer's bargaining ability would then determine the split of the surplus $p-m$ generated by a trade, where $m$ is the marginal cost of the good. Buyers differ with respect to bargaining ability. We do not explicitly model the negotiation process between the buyer and seller. Rather, we assume that there are two buyer types identified by their bargaining abilities $\gamma_{1}$ and $\gamma_{2}$, where $\gamma_{1}>\gamma_{2}$. Let $\delta \equiv \gamma_{1}-\gamma_{2}$ be the difference in buyer bargaining ability. With probability $\alpha$, the buyer's bargaining ability is $\gamma_{1}$ and with probability $1-\alpha$, it is $\gamma_{2}$. Dealers are unable to determine the buyer's bargaining ability and price discriminate, except through direct negotiation. When encountering a buyer through the intermediary, firm $A$ must quote a price based only on the information about the car the buyer has requested, the buyer's name, and an E-mail address or phone number. This information does not enable firm $A$ to determine a referred buyer's bargaining ability. In addition, a primary attraction of the referral system is the ability it offers weak bargainers to avoid haggling. In this respect, the intermediary provides firm $A$ with a commitment device which enables firm $A$ to establish a reputation for haggle-free sales to buyers encountered through the referral system. Negotiating with referred buyers would damage this reputation and make use of the intermediary less attractive to the buyers who are most likely to purchase through this channel. For these reasons, we treat the price $r$ offered through the referral system as non-negotiable ${ }^{8}$ whereas the price advertised by the local dealer is subject to bargaining.

\footnotetext{
${ }^{7}$ In the case of very popular automobile models, the negotiated selling price may actually exceed the suggested retail price. In this case, the valuation $v$ would simply represent the maximum amount the buyer is willing to pay.

${ }^{8}$ The assumption that the referral price is non-negotiable does not perfectly fit with the case of Autobytel. Scott Morton et al (2003) cite a report of J.D. Power and Associates that established that $42 \%$ of referred dealerships claim that their initial price offer to an Autobytel customer contains no room for negotiation, $42 \%$ quote a price but leave room for negotiation, while $14 \%$ quote a discounted price only if the customers insists by e-mail or phone and $2 \%$ do not quote a price until the customer comes to the dealership. However, it is not clear that buyers who use the referral system would choose to negotiate with firm A Good bargainers who reject $r$ in favor of bargaining have no incentive to negotiate with firm $A$ instead of negotiating with and purchasing from a local dealer. (In practice, a strong bargainer may use the price quote received from firm $A$ in an attempt to increase his or her bargaining leverage with the local dealer.) Furthermore, as demonstrated in the analysis of the model below, because a weak bargainer is unable to negotiate a price better than $r$, he or she is better off accepting $r$ and avoiding the disutility of engaging in a negotiation which will ultimately result in the same price. Scott Morton et al (2003) observed that prices at a referred dealer are less dispersed for buyers referred to the dealer by Autobytel than for buyers who are not referred. This suggests that the assumption that the referral price is non-negotiable is reasonable.
} 


\subsection{When non-referred sellers are non strategic}

We begin by considering the case in which non-referred sellers advertise a price of $p_{n}=v$. This is consistent with the results of Baye and Morgan (2001, 2002) and Chen et al (2002) who demonstrate in a posted price setting that firms will always charge the monopoly price to local, non-shopping customers. In this section, the non-referred sellers do not attempt to advertise a price less than $v$ in order to attract referred buyers away from firm $A$. In the next section, we consider an alternative version of the model in which the non-referred firms act strategically by advertising negotiable prices which may attract buyers who use the intermediary away from firm $A$.

Given $p_{n}=v$, a buyer who does not use the referral intermediary will negotiate a price $m+\gamma_{i}(v-m), \quad i=1,2$, and a buyer who uses the intermediary will only purchase from firm $A$ at the quoted price $r$ if $r<m+\gamma_{i}(v-m)$. If $r \geq m+\gamma_{i}(v-m)$, then the buyer will reject $r$ and bargain with his local dealer. Without loss of generality, we let $m=0$. The buyers' value $v$ can be thought of as the surplus over which the buyer and the dealer negotiate. When bargaining with a type $\gamma_{i}$ buyer, the dealer receives a net revenue of $\gamma_{i} v$, and the buyer's surplus is $\left(1-\gamma_{i}\right) v$.

Because buyers choose to use the intermediary with probability $\phi$, the primary role of the intermediary is to increase the rate at which buyers arrive at firm $A$ (and simultaneously reduce the rate at which buyers arrive at other dealer locations). In particular, rather than encountering buyers at the rate $\lambda / N$, firm $A$ encounters the fraction $1-\phi$ of buyers who do not use the intermediary with probability $1 / N$ and the fraction $\phi$ who do use the intermediary with probability 1 . Given the overall arrival rate $\lambda$ of buyers to the market, this implies that the rate at which buyers arrive at firm $A$ is $\lambda((1-\phi) / N+\phi)=\tilde{\lambda}$. Given this arrival rate, let $\tau$ be the random time at which a buyer arrives at firm $A$. Noting that $\tau$ is an exponential random variable with parameter $\tilde{\lambda}$, $E[\tau]=1 / \tilde{\lambda}$, and the expected cost incurred to interact with a buyer is $c / \tilde{\lambda}$.

Calculating firm $A$ 's expected return requires knowing whether a buyer arrives at firm $A$ through the intermediary and is quoted a price $r$ or arrives directly and negotiates a price $\gamma_{i} v$. The probability that a buyer who arrives at firm $A$ has been referred by the intermediary is determined by Bayes' rule as follows:

$$
\operatorname{Pr}(\text { referral } \mid \text { arrive })=\frac{\phi \cdot 1}{\phi \cdot 1+(1-\phi) \cdot \frac{1}{N}}=\frac{N \phi}{1+(N-1) \phi} \equiv \phi_{r} .
$$

Similarly, the probability that a buyer who arrives at firm $A$ did not use the intermediary is

$$
\operatorname{Pr}(\text { notreferral } \mid \text { arrive })=\frac{(1-\phi) / N}{\phi \cdot 1+(1-\phi) \cdot \frac{1}{N}}=\frac{1-\phi}{1+(N-1) \phi} \equiv \phi_{n r} .
$$


Because there are only two bargaining types, firm $A$ 's optimal referral price $r$ will be either $r=\gamma_{1} v$ or $r=\gamma_{2} v$. If $r=\gamma_{2} v$, then any buyer using the intermediary will purchase at the price $r$. If $r=\gamma_{1} v$, then weak bargainers will accept $r$, but good bargainers will reject $r$ and negotiate with a local dealer. Here, we assume that buyers who reject the referral price are randomly allocated to one of the non-referred firms (but do not negotiate with firm A). ${ }^{9}$ If a buyer rejects firm $A$ 's offer, then firm $A$ resumes search for another buyer. Thus, firm $A$ 's return when offering referred buyers a posted price of $r=\gamma_{1} v$ is

$$
R_{A}\left(\gamma_{1} v\right)=-c / \tilde{\lambda}+\phi_{r}\left[\alpha \gamma_{1} v+(1-\alpha) R_{A}\left(\gamma_{1} v\right)\right]+\phi_{n r} \bar{\gamma}
$$

where $\bar{\gamma} \equiv \alpha \gamma_{1}+(1-\alpha) \gamma_{2}$, so $\bar{\gamma}$ is the expected price the seller receives when bargaining with a non-referred customer. Firm $A$ incurs the cost $-c / \tilde{\lambda}$ to locate a buyer. With probability $\phi_{r}$, that buyer is referred by the intermediary. In this case, with probability $\alpha$, the buyer is a weak bargainer who accepts the offer and pays $\gamma_{1} v$, while with probability $1-\alpha$, the buyer is a strong bargainer who rejects the offer. This leaves the seller to resume search which has a value of $R_{A}\left(\gamma_{1} v\right)$. ${ }^{10}$ Thus, the expected value of a referred buyer is $\alpha \gamma_{1} v+(1-\alpha) R_{A}\left(\gamma_{1} v\right)$. With probability $\phi_{n r}$, the buyer is a local (not referred) buyer and the expected transaction price with a local buyer is $\bar{\gamma}$. Solving for $R_{A}\left(\gamma_{1} v\right)$ yields

$$
R_{A}\left(\gamma_{1} v\right)=\frac{-c / \tilde{\lambda}+\phi_{r} \alpha \gamma_{1} v+\phi_{n r} \bar{\gamma}}{1-\phi_{r}(1-\alpha)}
$$

Similarly, firm $A$ 's return when offering referred buyers a posted price of $\gamma_{2} v$ is

$$
R_{A}\left(\gamma_{2} v\right)=-c / \tilde{\lambda}+\phi_{r} \gamma_{2} v+\phi_{n r} \bar{v}
$$

Finally, firm $A$ can choose not to contract with the intermediary. In this case, the rate at which buyers arrive at firm $A$ is $\lambda / N$, and firm $A$ 's return, which we denote by $\widetilde{R}_{A}$ is

$$
\widetilde{R}_{A}=-N c / \lambda+\bar{\gamma} \text {. }
$$

Proposition 1. Let $\delta \equiv \gamma_{1}-\gamma_{2}$ denote the difference in buyer bargaining abilities, and

$$
\hat{\delta} \equiv \frac{(1-\alpha) N c / \lambda}{\alpha v[\phi(N-2)+2-\alpha(1-\phi)]} .
$$

Firm A will quote buyers who are encountered through the referral system a low price of $r=\gamma_{2} v$ if $\delta \leq \hat{\delta}$ and a high price of $r=\gamma_{1} v$ if $\delta>\hat{\delta}$.

Proof. See appendix.

\footnotetext{
${ }^{9}$ This assumption is made to simplify the analysis (particularly the arrival rate) and is modified in section 3 below.

${ }^{10}$ For simplicity, we assume that future returns are not discounted.
} 
Corollary 1 If $\delta \leq \hat{\delta}$ then buyers who use the referral system pay a price $r=\gamma_{2} v$ which is less than the average price $\bar{\gamma}$ paid by buyers who do not use the referral system.

If the difference in buyer bargaining abilities is small $(\delta<\hat{\delta})$, then firm $A$ will establish a referral price $r$ sufficiently low to ensure that good bargainers who use the intermediary buy at the referred price rather than visiting their local dealer to negotiate a price. However, if the difference in buyer bargaining abilities is large (so $\delta>\hat{\delta}$ ), then the referred firm prefers to raise the referral price and to obtain a high mark-up on weak bargainers, rather than retaining good bargainers with a low referral price. The implications of this result are discussed in more detail in subsection 2.2 below.

Proposition 1 contrasts with the findings of Chen et al (2002) and Ghose et al (2002) that the price paid through the referral system is systematically lower than the price paid by consumers who do not use the referral system. However, both their models assume that sellers use only a posted price mechanism. In our model, the price paid by consumers who use the referral system may be either greater or less than the average price paid by consumers who do not use the referral system (who bargain with the dealer directly). Assuming the difference in buyer bargaining abilities is sufficiently small, our findings are consistent with evidence provided by Scott Morton et al (2004) in which weak bargainers (whom they label "cowards") who use the referral system pay two percent less (on average) than cowards who negotiate directly with a dealer, while good bargainers (labeled "cowboys") obtain no price advantage through the referral system. However, we would not expect this result to hold if the difference in buyer bargaining abilities becomes sufficiently large.

Proposition 3. The range of the values of the difference $\delta$ in buyer bargaining abilities, for which firm A establishes a low referral price of $r=\gamma_{2} \mathrm{~V}$ is increasing in $c$ and $N$, is decreasing in $\lambda, v$, and $\alpha$, and is decreasing in $\phi$ provided $N>2$.

Proof. This follows directly from signs of the derivative of $\hat{\delta}$ with respect to the parameters $c, N, \lambda, v, \alpha$, and $\phi$.

Combined with proposition 1, proposition 3 implies that for given bargaining abilities $\gamma_{1}$ and $\gamma_{2}$, we will have $\delta<\widetilde{\delta}$, and firm $A$ will set a high referral price if either the search cost $c$ or number $N$ of firms is relatively low, or if the arrival rate $\lambda$, the consumer valuation $v$, or the proportion $\phi$ of consumers who use the referral system is relatively high. These comparative statics results have the following interpretation. A small value for $c$ or $N$, and a large value for $\lambda$ or $\phi$ all reduce the referred firm's incentive to set a low referral price because they reduce the search cost associated with locating another buyer if the seller fails to reach agreement with the current buyer. A large value of $\alpha$ implies a higher probability that a randomly arriving buyer will be a weak bargainer who will pay a high price. As $\alpha$ increases, the referred seller is more inclined to set a high referral price which is only attractive to weak bargainers because the probability this price will be rejected and the firm will incur additional search costs is decreasing in $\alpha$. Finally, a higher buyer valuation, or net surplus, $v$ reduces the referred firm's incentive to offer a 
low referral price because the price discount $\delta v$ required to capture referred customers who are good bargainers is increasing in $v$.

\subsection{Impact of the referral system on buyers}

The empirical findings of Scott Morton et al indicate that Autobytel benefits buyers by providing a lower price to Autobytel users, on average, than the average price achieved by buyers who negotiate directly with a dealer. Propositions 1 and 3 imply that in the simple market considered here, the price $r$ paid by buyers who purchase through the referral system will be less than the average price $\bar{\gamma}$ paid by buyers who do not use the referral system if $\delta \leq \hat{\delta}$. Perhaps more interestingly, the above results suggest that the referral system will not benefit buyers under all market conditions. ${ }^{11}$ For example, as the arrival rate $\lambda$ increases, the critical value $\hat{\delta}$ increases and firm $A$ is less likely to offer a discounted price (of $\gamma_{2} v$ ) to users of the referral system. This suggests that the referral system may not benefit buyers during periods of peak demand which correspond to a high arrival rate $\lambda$. Similarly, if the surplus $v$ (recall that $v$ can be interpreted as the difference between the MSRP and the seller's marginal cost) is relatively large, then the seller is less likely to offer a discount through the referral system. For example, if the manufacturer offers significant incentives to the dealer, which effectively reduce $m$, then the cost to the dealer of offering the best negotiated price to all users of the referral system increases. This may cause the dealer to offer less attractive pricing to buyers using the referral system. Finally, an increase in the fraction $\phi$ of buyers who use the referral system will reduce firm $A$ 's incentive to offer the price $r=\gamma_{2} v$.

\subsection{Viability of the referral system}

Contracting with the intermediary increases the rate at which buyers arrive at firm $A$, but it also requires firm $A$ to make a fixed price offer to buyers who use the referral system. This could be detrimental to firm $A$ for two reasons. First, if firm $A$ sets $r=\gamma_{2} v$, then it will sell to the referred type $\gamma_{1}$ buyers at a price below the price it would negotiate with these buyers in the absence of a referral system. Second, if firm $A$ sets $r=\gamma_{1} v$, it will lose sales to the referred type $\gamma_{2}$ buyers, and this reduces the benefit of an increased arrival rate offered by the intermediary. To determine whether the referral system is viable, consider the surplus $S \equiv R_{A}\left(\gamma_{i} v\right)-\widetilde{R}_{A}$ generated by the intermediary. Proposition 1 implies that $S=R_{A}\left(\gamma_{2} v\right)-\widetilde{R}_{A}$ if $\delta \leq \hat{\delta}$, and $S=R_{A}\left(\gamma_{1} v\right)-\widetilde{R}_{A}$ if $\delta>\hat{\delta}$.

\footnotetext{
${ }^{11}$ It is reasonable to ask why buyers would use the referral system if they do not benefit in terms of a lower transaction price. Weak bargainers will have an incentive to request a quote because they can achieve the same price, $\gamma_{1} v$, without having to engage in a negotiation process. Even good bargainers would perceive a benefit from requesting a quote if they are not sure about the exact value of $\delta$ or $\hat{\delta}$, so there is some possibility that the referred firm will quote a price of $r=\gamma_{2} v$ and they can avoid negotiating a price. In addition, strong bargainers may attempt to use the quoted price as a bargaining chit with a local dealer.
} 
Proposition 4. The surplus $S$ generated by the intermediary is strictly positive, and $S$ is increasing in $N$ and $\phi$. In addition, if $\delta \leq \hat{\delta}$, then $S$ is decreasing in $\delta$ and $v$, and if $\delta>\hat{\delta}$, then $S$ is increasing in $\delta$ and $v$.

Proof. See appendix.

Proposition 4 implies that firm $A$ will always prefer to enter into an agreement with the intermediary (provided the intermediary's fee does not exceed $S$ ). Furthermore, because the surplus generated by the intermediary is strictly increasing in the proportion $\phi$ of buyers who use the referral system, the intermediary has an incentive to maximize consumer participation. The fact that $S$ increases in $N$ implies that intermediaries may be more likely to appear in markets with many dealers. The dependence of the comparative static results for the remaining parameters on whether $\delta$ is less than or greater than $\hat{\delta}$ highlights the trade-off between the increased arrival rate and corresponding reduction in search costs gained by offering a fixed price to customers who use the intermediary, and the ability to extract the maximum possible surplus the dealer can achieve by bargaining. For example, when the difference in buyer bargaining abilities is small, so $\delta<\hat{\delta}$, the impact of the reduced search cost offered by the intermediary is relatively more important than extracting more surplus through bargaining because the difference $\delta v$ in surplus to be gained by negotiating with a weak bargainer is small.

\section{When local sellers compete for buyers}

In many markets, non-referred dealers are not passive and can take into account the behavior of the referred firm. For example, non-referred dealers can anticipate the discount that buyers who use the referral system will be quoted by firm $A$. We now consider the case in which local dealers can advertise a price $p_{n}$ less than $v$ in order to compete for buyers who use the referral system. The firms engage in the following game. In the first period, firm $A$ chooses whether or not to enter into an exclusive agreement with the intermediary. If firm $A$ chooses not to use the referral system, when a buyer arrives at the market (according to the Poisson process with rate $\lambda$ ), he is randomly allocated to and negotiates a price with one of the $N$ dealers. If firm $A$ contracts with the intermediary, then the dealers engage in price competition à la Stackelberg in which the non-referred firms act as leaders relative to firm $A$. The assumption that the firm $A$ is the follower is consistent with the fact that prices advertised by non-referred dealers, typically printed in local newspapers or made public through other media, are more difficult to change than the referral price which firm $A$ privately communicates to each referred buyer via E-mail or a phone call. Each non-referred firm sets an advertised price $p_{n}$, which serves as a starting point for the bargaining process. Firm $A$ then establishes its advertised price $p_{A}$ and referral price $r$. Buyers who use the referral system observe the referral price $r$ and either accept $r$ or reject $r$ and negotiate with a local dealer. Buyers who do not use the referral system are randomly allocated to one of the $N$ firms and negotiate a price.

We assume the $N-1$ non-referred sellers are symmetric and compete with firm $A$ for buyers who use the referral system. We consider only symmetric equilibria in which the 
$N-1$ non-referred firms all establish the same advertised price $p_{n}$. As above, the price a buyer bargains with the seller depends upon the buyer's bargaining ability; a type $\gamma_{i}$ buyer negotiates a price of $\gamma_{i} p_{n}$ with a non-referred seller. ${ }^{12}$ Rather than determining the share of the total surplus $v$ captured by the seller, the buyer's bargaining ability $\gamma_{i}$ now determines the share of the advertised price captured by the seller. By advertising a price $p_{n}<v$, the seller concedes an amount $v-p_{n}$ of the surplus. Such a concession will be optimal only if the resulting loss in revenue induces some buyers who use the referral system to reject the referral price in favor of bargaining with a local dealer.

\subsection{All buyers use the referral system}

To simplify the analysis and to focus on the impact of the referral system on the competitive pricing decisions of each firm, in this subsection, we assume that all buyers use the referral system, so that $\phi=1$. After establishing this benchmark case, the case of $\phi \in(0,1)$ is discussed briefly in subsection 3.2. Under the simplifying assumption that $\phi=1$, the probability $\phi_{r}$ that a buyer arriving at a dealer's location has received a quote from the referred dealer is $\phi_{r}=1^{13}$ and the arrival rate $\tilde{\lambda}=\lambda$.

\subsubsection{Pricing strategy of the referred firm}

Because a type $\gamma_{i}$ buyer negotiates a price $\gamma_{i} p_{n}$ when bargaining with his local dealer, the optimal referred price $r$ for firm $A$ will be either $r=\gamma_{1} p_{n}$, which captures only the weak bargainers who use the referral system or $r=\gamma_{2} p_{n}$, which captures all buyers who use the referral system. Although establishing a low referral price of $\gamma_{2} p_{n}$ enables firm $A$ to sell the item more quickly (thereby reducing its operating costs), it also entails an expected loss in revenue of $\alpha\left(\gamma_{1}-\gamma_{2}\right) p_{n}$. This loss reflects the fact that if the referred buyer is a bad bargainer (which occurs with probability $\alpha$ ), then he is willing to purchase the item at the higher price $\gamma_{1} p_{n}$. To explicitly account for the strategic interaction between the price advertised by non-referred sellers and the rate at which buyers arrive and purchase from each seller, we assume that in addition to its arrangement with the intermediary, firm $A$ also serves as a local dealer for some buyers. The probability that a referred buyer who rejects $r$ is reassigned to any given dealer (including firm $A$ ) is $1 / N$.

Firm $A$ 's return when advertising a price $p_{A}{ }^{14}$ and quoting a referred price of $r=\gamma_{1} p_{n}$ is

$$
R_{A}\left(p_{A}, \gamma_{1} p_{n}\right)=-c / \lambda+\alpha \gamma_{1} p_{n}+(1-\alpha)\left(\frac{1}{N} \gamma_{2} p_{A}+\frac{N-1}{N} R_{A}\left(p_{n}, \gamma_{1} p_{n}\right)\right) .
$$

\footnotetext{
${ }^{12}$ Recall that without loss of generality the seller's marginal cost $m$ has been set to $m=0$.

${ }^{13}$ And the probability that a buyer arriving at a local dealer did not use the intermediary is $\phi_{n r}=0$.

${ }^{14}$ Note that only buyers who reject the referral price and who are in firm A's local market actually observe the price $p_{A}$ advertised by firm $A$. Thus, the probability that a given referred buyer ends up rejecting $r=\gamma_{1} p_{n}$ and trading with firm $A$ through firm A's local market is $(1-\alpha) \frac{1}{N}$.
} 
Solving for $R_{A}\left(p_{A}, \gamma_{1} p_{n}\right)$ yields

$$
R_{A}\left(p_{A}, \gamma_{1} p_{n}\right)=\frac{-c / \lambda+\alpha \gamma_{1} p_{n}+(1-\alpha) \gamma_{2} p_{A} / N}{[1+\alpha(N-1)] / N}
$$

If firm $A$ offers a referral price of $r=\gamma_{2} p_{n}$, then it will capture all buyers, regardless of its advertised price, ${ }^{15}$ and its return is

$$
R_{A}\left(p_{A}, \gamma_{2} p_{n}\right)=-c / \lambda+\gamma_{2} p_{n}
$$

Establishing a high referral price of $\gamma_{1} p_{n}$ which attracts only type 1 customers will be optimal for firm $A$ if and only if $R_{A}\left(v, \gamma_{1} p_{n}\right) \geq R_{A}\left(p_{A}, \gamma_{2} p_{n}\right)$, or

$$
\frac{-c / \lambda+\alpha \gamma_{1} p_{n}+(1-\alpha) \gamma_{2} p_{A} / N}{[1+\alpha(N-1)] / N} \geq-c / \lambda+\gamma_{2} p_{n} .
$$

Define $\widetilde{p}_{n}$ as

$$
\widetilde{p}_{n} \equiv \frac{(1-\alpha)\left[(N-1) c / \lambda-\gamma_{2} p_{A}\right]}{\alpha N \gamma_{1}-[1+\alpha(N-1)] \gamma_{2}}
$$

so that equation (6) is satisfied with equality when local dealers advertise $p_{n}=\widetilde{p}_{n}$. The following lemma characterizes the optimal referral price $r$.

Lemma 5 Let $\Delta \equiv \frac{\alpha N}{1+\alpha(N-1)}<1$.

First, suppose $p_{A} \geq((N-1) c / \lambda) / \gamma_{2}$.

- If $\frac{\gamma_{2}}{\gamma_{1}} \leq \Delta$ (strong heterogeneity in customers' bargaining abilities), then the optimal referral price for firm $A$ is $r=\gamma_{1} p_{n}$, regardless of the value of $p_{n}$.

- If $\frac{\gamma_{2}}{\gamma_{1}}>\Delta$ (small heterogeneity), then the optimal referral price is $r=\gamma_{1} p_{n}$ if $p_{n} \leq \widetilde{p}_{n}$ and $r=\gamma_{2} p_{n}$, if $p_{n}>\widetilde{p}_{n}$.

Next, suppose $p_{A}<((N-1) c / \lambda) / \gamma_{2}$.

\footnotetext{
${ }^{15}$ Because all buyers are referred to firm $A$ and will pay a price of at least $\gamma_{2} p_{n}$, firm $A$ would never advertise a price less than $p_{n}$, so we can assume $p_{A} \geq p_{n}$ when firm $A$ sets $r=\gamma_{2} p_{n}$.
} 
- If $\frac{\gamma_{2}}{\gamma_{1}} \leq \Delta$ (strong heterogeneity), then the optimal referral price for firm $A$ is $r=\gamma_{1} p_{n}$ if $p_{n} \geq \widetilde{p}_{n}$, and $r=\gamma_{2} p_{n}$, if $p_{n}<\widetilde{p}_{n}$.

- If $\frac{\gamma_{2}}{\gamma_{1}}>\Delta$ (small heterogeneity), then the optimal referral price is $r=\gamma_{2} p_{n}$ regardless of the value of $p_{n}$.

Proof. See appendix.

This lemma demonstrates that the referral price established by firm $A$ will depend both upon the advertised price $p_{A}$ that firm $A$ is able to establish for good bargainers who refuse to purchase at the referral price $r$, as well as on the difference in buyer bargaining abilities. If firm $A$ establishes a high advertised price $p_{A} \geq((N-1) c / \lambda) / \gamma_{2}$ and the difference in buyer bargaining abilities is large (so that $\gamma_{2} / \gamma_{1}$ is small), then firm $A$ will never choose a low referral price and will retain only the weak bargainers. Firm $A$ will not compete to retain good bargainers for two reasons. First, the large difference in bargaining abilities implies that the discount $\left(\gamma_{1}-\gamma_{2}\right) p_{n}$ that must be offered in order to retain the good bargainers is large. Second, because the advertised price $p_{A}$ is high, the price that firm $A$ negotiates with the fraction $1 / N$ of the good bargainers who reject $r$ is high as well. If, however, there is little difference in buyer bargaining abilities ( $\gamma_{2}$ close to $\left.\gamma_{1}\right)$, then the discount $\left(\gamma_{1}-\gamma_{2}\right) p_{n}$ required to retain good bargainers through the referral system is small and firm $A$ will compete to retain all good bargainers by setting $r=\gamma_{2} p_{n}$, as long as the non-referred firms do not price too competitively, (that is, as long as the nonreferred firms advertise a price $\left.p_{n}>\widetilde{p}_{n}\right)$. But if $p_{n} \leq \widetilde{p}_{n}$, then it is optimal for firm $A$ to establish a high referral price $\left(r=\gamma_{1} p_{n}\right)$ attractive only to the weak bargainers and to negotiate directly with its share $1 / N$ of the good bargainers.

If firm $A$ establishes a low advertised price $p_{A}<((N-1) c / \lambda) / \gamma_{2}$ and the difference in buyer bargaining abilities is small, then firm $A$ will always set $r=\gamma_{2} p_{n}$ to retain good bargainers. In this case, the cost incurred to retain good bargainers through the referral system is small, whereas the expected benefit from bargaining with good bargainers is low (because $p_{A}$ is small). However, if the difference in bargaining abilities is large, then firm A will only compete for good bargainers $\left(r=\gamma_{2} p_{n}\right)$ if the non-referred firms establish a relatively low advertised price $\left(p_{n}<\widetilde{p}_{n}\right)$, so that the discount required to retain good bargainers is small. If the non-referred firms set a high asking price of $p_{n} \geq \widetilde{p}_{n}$, then it is optimal for firm $A$ to concede good bargainers in order to charge a high referral price of $r=\gamma_{1} p_{n}$ to weak bargainers.

To determine the optimal advertised price for firm $A$, note that because $p_{A}$ serves only as the starting point for negotiation with a good bargainer, firm $A$ would like to set $p_{A}$ as high as possible. Maximizing (4) with respect to $p_{A}$ subject to the constraint that $p_{A} \leq v$ yields $p_{A}=v$. This is similar to the outcome in Baye and Morgan $(2001,2002)$ 
and Chen et al (2002) in which the referred seller sets the monopoly price for transactions with non-shopping, local customers. However, as demonstrated in lemma 6, firm A will not always be able to advertise $p_{A}=v$ because good bargainers can always purchase at the referral price $r$ which may be less than $\gamma_{2} v$. In particular, if $r=\gamma_{1} p_{n}$, then the good bargainers will negotiate with firm $A$ only if they obtain a price $\gamma_{2} p_{A}$ lower than $\gamma_{1} p_{n}$. This implies that firm $A$ cannot advertise a price $p_{A}$ higher than $\frac{\gamma_{1}}{\gamma_{2}} p_{n}$.

Lemma 6. Firm $A$ will set an advertising price $p_{A}=\min \left\{v, \frac{\gamma_{1}}{\gamma_{2}} p_{n}\right\}$.

Proof. See appendix.

We now turn to the strategy of the non-referred firms to determine the conditions under which $p_{n} \leq \widetilde{p}_{n}$.

\subsubsection{Pricing strategy of the non-referred firms}

Given the assumption that $\phi=1$, the non-referred firms must set a price $p_{n}$ which attracts only the good bargainers away from firm $A$. If non-referred firms establish a price $p_{n}$ such that good bargainers prefer the referral price, then the non-referred firms will have no customers. Similarly, if the non-referred firms attract both good and bad bargainers away from firm $A$, then firm $A$ will have no customers. Neither of these cases can be sustained in equilibrium. A unique stable configuration is characterized by the referred firm selling to the bad bargainers at a fixed price and bargaining with a fraction $1 / N$ of good bargainers and the non referred firms bargaining with the remaining good bargainers. Consumers will arrive at any given non-referred firm at the rate $\lambda(1-\alpha) / N$, and each nonreferred firm's return is

$$
R_{n}\left(p_{n}\right)=-c N /(\lambda(1-\alpha))+\gamma_{2} p_{n} .
$$

Because non-referred firms cannot sell at a price $p_{n}>v, v \geq \frac{c N / \lambda}{\gamma_{2}(1-\alpha)}$ is a necessary condition for non-referred firms to participate in the market. In addition, non-referred firms must advertise at a price sufficiently low to attract good bargainers away from firm $A$ in order to make any sales. In the analysis below, we allow for the possibility that nonreferred firms make no sales. This will occur for certain market parameters under which it is optimal for firm $A$ to adopt a limit pricing strategy which captures all buyers through the referral system.

\section{Proposition 7. Equilibrium Pricing Strategies}

- If $\frac{\gamma_{2}}{\gamma_{1}} \leq \Delta$ (strong heterogeneity in customers' bargaining abilities), then in equilibrium, the non-referred firms advertise a price $p_{n}=v$, and firm $A$ 
advertises $p_{A}=v$. If, in addition, $v \geq \frac{(1-\alpha)(N-1) c / \lambda}{\alpha N\left(\gamma_{1}-\gamma_{2}\right)}$, then firm $A$ sets a referral price of $r=\gamma_{1} v$ and sells only to weak bargainers who use the referral system, while if $v<\frac{(1-\alpha)(N-1) c / \lambda}{\alpha N\left(\gamma_{1}-\gamma_{2}\right)}$, then $r=\gamma_{2} v$ and all buyers purchase through the referral system.

- If $\frac{\gamma_{2}}{\gamma_{1}}>\Delta$ (small heterogeneity) and $v \geq((N-1) c / \lambda) / \gamma_{2}$, then in equilibrium, the non-referred firms set $p_{n}=\min \left\{v, \frac{(1-\alpha)(N-1) c / \lambda}{\left(\gamma_{1}-\gamma_{2}\right)(1+\alpha(N-1))}\right\}$, and firm $A$ advertises $p_{A}=\min \left\{v, \frac{\gamma_{1}}{\gamma_{2}} p_{n}\right\}$, and sets $r=\gamma_{1} p_{n}$.

- If $\frac{\gamma_{2}}{\gamma_{1}}>\Delta$ and $v<((N-1) c / \lambda) / \gamma_{2}$, then in equilibrium, firm $A$ sets $r=\gamma_{2} p_{n}$ and captures all buyers through the referral system, the non-referred firms can set any advertised price $p_{n} \in\left((c / \lambda) / \gamma_{2}, v\right]$, and firm $A$ will advertise $p_{A} \geq p_{n}$.

Proof. See appendix.

Proposition 7 provides several insights into the impact of the referral system on new automobile prices. Perhaps most notable, is the fact that the referral system may have no impact on prices. As was the case in proposition 1, buyers may not realize a lower price through the referral system if the difference in bargaining abilities is sufficiently large. Indeed, if $\gamma_{2} / \gamma_{1}<\Delta$ and $v$ is large, then the discount $\left(\gamma_{1}-\gamma_{2}\right) v$ in the referral price that firm $A$ must offer to retain good bargainers is too large to justify competing for these buyers even if non-referred firms advertise a price $p_{n}=v$. There is no need for nonreferred firms to establish a low advertised price to attract good bargainers - firm $A$ willingly concedes these buyers. If $\Delta>\gamma_{2} / \gamma_{1}$ and $v$ is small $\left(v<\frac{(1-\alpha)(N-1) c / \lambda}{\alpha N\left(\gamma_{1}-\gamma_{2}\right)}\right)$, then the magnitude of the discount $\delta v$ that firm $A$ must offer to retain good bargainers will be justified. In this case, a reduction in $p_{n}$ by the non-referred dealers is futile because setting an advertised $p_{n}<v$ only serves to further reduce the discount $\delta p_{n}$ which firm $A$ needs to offer to attract good bargainers; firm $A$ captures all buyers with a referral price of $r=\gamma_{2} v$. The threat of losing buyers provides a sufficient incentive for firm $A$ to set a referral price which is attractive to all buyers; $r=\gamma_{2} v$ is a limit price that deters good bargainers from visiting their local dealers.

If $v$ is large and the difference in buyer bargaining abilities is sufficiently small, then the referral system causes non-referred firms to advertise $p_{n}<v$, and firm $A$ is just indifferent between selling to all buyers with a referral price $\gamma_{2} p_{n}$, or selling to weak 
bargainers at a higher referral price of $r=\gamma_{1} p_{n}$ and negotiating a price $\gamma_{2} p_{A}$ with its share of the good bargainers. As a result, in equilibrium, the non-referred dealers offer $p_{n}<v$ to capture the good bargainers. Finally, if the difference in bargaining abilities is small and $v$ is small, then firm $A$ adopts a limit price and retains all buyers who use the referral system by setting $r=\gamma_{2} p_{n}$.

The following proposition summarizes the impact of the referral system on market prices.

Proposition 8. When all buyers use the referral system:

- If $\frac{\gamma_{2}}{\gamma_{1}} \leq \Delta$ (strong heterogeneity in customers' bargaining abilities) and $v \geq \frac{(1-\alpha)(N-1) c / \lambda}{\alpha N\left(\gamma_{1}-\gamma_{2}\right)}$, then each buyer type pays the same price in a market with a referral intermediary as they would in a market without the intermediary.

- If $\frac{\gamma_{2}}{\gamma_{1}}>\Delta$ and $v>\max \left\{((N-1) c / \lambda) / \gamma_{2}, \frac{(1-\alpha)(N-1) c / \lambda}{\left(\gamma_{1}-\gamma_{2}\right)(1+\alpha(N-1))}\right\}$, then weak bargainers pay a fixed price $\gamma_{1} p_{n}$ which exceeds the average negotiated price in the market, but is less than the price $\gamma_{1} v$ they would pay in a market without the intermediary. Strong bargainers pay $\gamma_{2} p_{n}<\gamma_{2} v$, so all buyers pay a lower price in a market with the referral intermediary.

- For all other ranges of $v$ and $\gamma_{2} / \gamma_{1}$, firm $A$ sets a referral of $r \leq \gamma_{2} v$, and all buyers accept the price $r$ offered by firm $A$. The price paid by weak bargainers is strictly less than the price they would pay in the absence of the referral intermediary, and the price paid by strong bargainers is never greater than and may be less than the price they would pay in the absence of the intermediary.

Proof. See appendix.

Proposition 8 follows directly from proposition 7 and highlights conditions under which weak bargainers benefit from the referral system. It implies that if the difference in buyer bargaining abilities is large and the reservation value $v$ is large, then the referral system will not induce a reduction in the price paid by any buyer. However, if either $v$ is small or buyer bargaining abilities are sufficiently close, then the referral system will reduce the average price in the market. The results in proposition 8 also can be interpreted in the spirit of Wilde and Schwartz (1979) who show that shoppers generate a positive externality for non-shoppers by forcing competition between sellers, if and only if, the proportion of shoppers in the market exceeds a critical value. As the proportion $\alpha$ of weak bargainers goes to $0, \Delta \rightarrow 0$ as well, so $\frac{\gamma_{2}}{\gamma_{1}}>\Delta$ and proposition 8 implies that the referral 
system reduces the average market price. ${ }^{16}$ With the referral system, if the fraction of good bargainers is sufficiently large, then they confer a positive externality on all buyers by reducing prices for at least some buyers.

\subsubsection{Viability of the referral system}

Proposition 8 provides a necessary, but not sufficient condition for the referral system to reduce the average price in the market because when $\frac{\gamma_{2}}{\gamma_{1}}>\Delta$ is satisfied, it may be suboptimal for firm $A$ to contract with the intermediary. The referral system will be viable if all dealers receive non-negative returns when adopting the optimal pricing strategies derived in subsections 3.1.1 and 3.1.2, and if firm $A$ is better off contracting with the intermediary, that is, if $R_{A}\left(v, \gamma_{1} p_{n}\right)>\widetilde{R}_{A}$ where $\widetilde{R}_{A}=-N c / \lambda+\bar{\gamma} v$ is firm A's return without an intermediary. ${ }^{17}$

Proposition 9. When all buyers use the referral system:

- If $\frac{\gamma_{2}}{\gamma_{1}} \leq \Delta$ and $v \geq \frac{(1-\alpha)(N-1) c / \lambda}{\alpha N\left(\gamma_{1}-\gamma_{2}\right)}$, then the surplus $S=R_{A}\left(v, \gamma_{1} p_{n}\right)-\widetilde{R}_{A}$ generated by the intermediary is strictly positive and is increasing in $N, C$ and $v$ and is decreasing in $\lambda$.

- If $\frac{\gamma_{2}}{\gamma_{1}} \leq \Delta$ and $v<\frac{(1-\alpha)(N-1) c / \lambda}{\alpha N\left(\gamma_{1}-\gamma_{2}\right)}$ or if $\frac{\gamma_{2}}{\gamma_{1}}>\Delta$ and $\frac{(1-\alpha)(N-1) c / \lambda}{\left(\gamma_{1}-\gamma_{2}\right)(1+\alpha(N-1))}>v \geq((N-1) c / \lambda) / \gamma_{2}$, then the surplus $S=R_{A}\left(v, \gamma_{2} p_{n}\right)-\widetilde{R}_{A}$ is strictly positive and is increasing in $\mathrm{N}$ and $\mathrm{c}$ and decreasing in $\lambda, v$, and $\alpha$.

${ }^{16}$ Note that as $\alpha \rightarrow 1$ (so most buyers are weak bargainers), $\Delta \rightarrow 1$ and $\frac{(1-\alpha)(N-1) c / \lambda}{\alpha N\left(\gamma_{1}-\gamma_{2}\right)} \rightarrow 0$, so $\frac{\gamma_{2}}{\gamma_{1}} \leq \Delta$ and $v>\frac{(1-\alpha)(N-1) c / \lambda}{\alpha N\left(\gamma_{1}-\gamma_{2}\right)}$ and the referral system does not lead to a reduction in prices. However, as $\gamma_{2} \rightarrow \gamma_{1}$ (less heterogeneity in bargaining abilities), then $\frac{\gamma_{2}}{\gamma_{1}}>\Delta$ and $v<\frac{(1-\alpha)(N-1) c / \lambda}{\alpha N\left(\gamma_{1}-\gamma_{2}\right)}$ so proposition 7 implies that $r<\gamma_{2} v$ and the referral system reduces the price paid by all buyers (relative to the price they would pay in the absence of a referral intermediary).

${ }^{17}$ Note that because $\widetilde{p}_{n} \leq 0$ when $\frac{\gamma_{2}}{\gamma_{1}}>\Delta$, and non-referred firms set $p_{n} \leq \widetilde{p}_{n}$ when $\frac{\gamma_{2}}{\gamma_{1}} \leq \Delta$, firm A will never choose to establish a referral price of $r=\gamma_{2} p_{n}$, that is, $R_{A}\left(v, \gamma_{1} p_{n}\right)>R_{A}\left(v, \gamma_{2} p_{n}\right)$ for all $p_{n}$ set optimally by the non-referred dealers. As result, non existence of an equilibrium due to firm $A$ pricing in a way that causes the non-referred dealers to exit the market is not an issue. 
- If $\frac{\gamma_{2}}{\gamma_{1}}>\Delta$ and $v \geq \max \left\{\frac{(1-\alpha)(N-1) c / \lambda}{\left(\gamma_{1}-\gamma_{2}\right)(1+\alpha(N-1))},((N-1) c / \lambda) / \gamma_{2}\right\}$, then the surplus

$$
S=R_{A}\left(p_{A}, \gamma_{1} p_{n}\right)-\widetilde{R}_{A} \text { is positive if }
$$$$
v<\frac{(N-1) c / \lambda}{\bar{\gamma}(1+\alpha(N-1))} \frac{(1-\alpha) \gamma_{1}+\alpha N\left(\gamma_{1}-\gamma_{2}\right)}{\gamma_{1}-\gamma_{2}} \equiv \hat{v} \text { and negative if } v>\hat{v} \text {. }
$$

\section{Proof. See appendix.}

The comparative statics results in proposition 9 are generally consistent with those in proposition 4. However, in contrast to the results in proposition 4, when we allow for competitive pricing by the non-referred dealers, $S<0$ is possible. If price competition for good bargainers by non-referred dealers is strong (in particular, if $\left.p_{n}<\frac{-\alpha N(N-1) c / \lambda}{\gamma_{1}(1+\alpha(N-1))}+\frac{\bar{\gamma}}{\gamma_{1}}\right)$, then firm A will choose not to contract with the intermediary. As shown in proposition 9, this outcome will occur if bargaining abilities are close and $v$ is relatively large. Under these market conditions, there is strong competition to attract good bargainers. The high reservation value $v$ creates a large surplus which gives nonreferred dealers a strong incentive to attract good bargainers, while the small difference in buyer bargaining abilities gives firm $A$ a strong incentive to offer the reduction $\left(\gamma_{1}-\gamma_{2}\right) p_{n}$ in price needed to retain good bargainers. The resulting reduction in transaction prices leads to a negative surplus from the intermediary. However, as $v$ decreases, dealers have less incentive to reduce prices to attract or retain good bargainers and it is possible for dealers to earn positive returns even with $p_{n}<v$.

\subsection{Limited reach of the referral system, $\phi \in(0,1)$}

In this subsection, we briefly discuss the implications of the model in which non-referred sellers can advertise a price $p_{n}<v$, in an attempt to compete with firm $A$ for referred customers and in which $\phi<1$, so not all buyers use the referral system. The primary difference between the model with $\phi<1$ and the model with $\phi=1$ follows from the additional allocations of buyers across firms that can occur when $\phi<1$. Recall that if $\phi=1$, then in any equilibrium, the non-referred firms sell only to good bargainers or capture no buyers at all. When $\phi<1$, the non-referred firms sell to the fraction $1-\phi$ of customers who do not use the referral system regardless of whether or not they choose to compete with firm $A$ for good bargainers who do use the referral system.

The main impact of these additional potential outcomes is to slightly reduce the competitive effect of the referral system. Under some market conditions which result in lower transaction prices when $\phi=1$, it is possible that with $\phi<1$, non-referred dealers will concede buyers who use the referral system to firm $A$ in favor of setting a higher advertised price $p_{n}=v$ and selling only to those buyers who do not use the referral system. Otherwise, the intuition presented in the analysis above continues to apply. For example, focusing on the fraction $\alpha$ of weak bargainers in the market, if $\alpha$ is large, then firm $A$ will compete to retain weak bargainers who use the referral system but not to 
retain strong bargainers because the fraction of strong bargainers is not sufficiently large to justify such competition. As a result, non-referred dealers advertise a price $p_{n}=v$ and firm $A$ sets $r=\gamma_{1} v$. As the fraction $\alpha$ of weak bargainers decreases, all firms adopt a more competitive posture with respect to the good bargainers. In equilibrium, firm $A$ sets a referral price of $r=\gamma_{1} p_{n}$ in order to sell to the weak bargainers who use the referral system but the price advertised by the non-referred dealers is sufficiently low to deter firm A from reducing the referral price to retain good bargainers. As the fraction of good bargainers increases further, firm $A$ will reduce $r$ to retain both the strong and weak bargainers who use the referral system. In this case, the non-referred dealers acquiesce by advertising a price of $p_{n}=v$ and selling only to local customers but firm $A$ must set a low referral price of $r=\gamma_{2} v$ to induce all buyers who use the referral system to purchase at the referral price $r$. Finally, if the difference in buyer bargaining abilities is very large, then the referred dealer will not compete for good bargainers encountered through the referral system. This result is intuitive. For a given proportion of bad bargainers, if the heterogeneity in bargaining ability is sufficiently large, then the discount $\left(\gamma_{1}-\gamma_{2}\right) p_{n}$ that the referred dealer would have to offer in order to entice both strong and weak bargainers to purchase through the referral system would not be justified. ${ }^{18}$

\section{Conclusion}

This paper contributes to the growing literature that explores how online markets impact the way in which prices are established. We consider the specific case of the market for new automobiles in which consumers have traditionally negotiated a transaction price with an individual dealer. The Internet has changed this market by enabling consumers to obtain non-negotiable price quotes online. We construct a model in which an online intermediary, like Autobytel.com, offers an exclusive contract to refer buyers who request a price offer from Autobytel to one of $N$ automobile dealers. The referred dealer offers to sell the good to buyers it encounters through the online intermediary at a fixed price $r$ and bargains with buyers it encounters directly at its local dealership.

Our analysis suggests several conclusions regarding the impact of a referral infomediary on the new automobile market. First, provided the difference in buyer bargaining abilities is not too large, buyers who use the referral service will pay a lower price, on average, than buyers who do not use the referral service. In this case, weak bargainers benefit the most from the referral system. This corresponds with the empirical results of Scott Morton, Zettlemeyer and Silva Risso (2001, 2003, 2004, 2006) who find that buyers who use Autobytel pay 2\% less on average than buyers who do not use Autobytel. ${ }^{19}$ However, our model predicts that these results could be overturned if the difference in buyer bargaining abilities increases, the value of the item being purchased

\footnotetext{
${ }^{18}$ Determining conditions under which the referral system is viable is substantially more complex when $\phi<1$.

${ }^{19}$ Scott-Morton et al also present empirical results consistent with bargaining theory. Car buyers who visited several dealers and who obtained an offer from a competing dealer paid less $(0.6 \%)$. Similarly, buyers who reported collecting information on the car they eventually purchased paid lower prices $(0.9 \%)$. Buyers who were willing to postpone their purchase should negotiations with the dealer break down paid lower prices $(0.6 \%)$. The combined savings of these effects equalled one-third of the average dealer margin.
} 
increases, or the fraction of consumers who request a price quote through the referral intermediary becomes too large. This could explain the only marginally significant (at the $10 \%$ level) and small impact of Autobytel on prices in the luxury car category obtained by Scott Morton et al (2001). For all other car categories, the coefficient on the Autobytel variable is negative and statistically significant at the $1 \%$ level. Our results imply that the referred dealer will not offer a below average price to buyers who use the referral system if the value $v$ of the item is sufficiently large because the magnitude of the price reduction required to entice good bargainers to purchase at the referral price (instead of rejecting the referral price and bargaining with a local dealer) is increasing in $v$. As a result, if $v$ is sufficiently large, which is most likely to be true for luxury cars, the referral price will exceed the average negotiated price. Because the manufacturer's suggested retail price (MSRP) of each automobile is readily observed and is a proxy for $v$, further empirical research investigating the impact of MSRP on the difference in the price paid by buyers who do and do not use the referral intermediary may provide additional insights into how intermediaries like Autobytel impact new automobile prices.

Our analysis also implies that in a market with an established intermediary, an increase in the fraction $\phi$ of buyers who utilize the referral service or an increase in the number $N$ of firms in the market can actually lead to an increase in average prices. This occurs because as $\phi$ increases, non-referred dealers lose a larger share of their local customers to the referred firm. Non-referred dealers respond to this by reducing their advertised price in an attempt to provide local customers a better deal than the fixed price offer obtained by using the referral system. At some point, the referred firm is better off conceding good bargainers who use the referral system and quoting a higher referral price which is attractive only to weak bargainers. Given the steady increase in the percentage of buyers who use the Internet to research new cars, our results suggest that over time, the ability of referral intermediaries to connect buyers with a dealer that offers referred customers a price below the market average will diminish. As this occurs, intermediaries will be forced to pursue other strategies to create value for users. In fact, this already may be occurring in the market for new automobiles. As opposed to past years in which Autobytel emphasized the price advantages of its website, ${ }^{20}$ Autobytel now emphasizes its product information content and automobile-related services such as financing and insurance.

Our analysis has been restricted to the case of Autobytel and the automobile industry. However, our approach could be used to analyze other types of intermediaries. For example, a model of how Priceline.com or eBay has influenced the price setting process and market equilibrium prices remains a topic for future research.

\section{$5 \quad$ References}

Arnold, M. A. and S. Lippman (1998) "Posted Prices versus Bargaining in Markets with Asymmetric Information,” Economic Inquiry, 36: 450-457.

Arnold, M.A. and C. Saliba. (2002) "Price Dispersion in Online Markets: The Case of College Textbooks," Working Paper, Department of Economics, University of Delaware.

\footnotetext{
${ }^{20}$ At one point, the Autobytel home page referenced the work of Scott Morton et al and their estimate of the $1.6 \%$ to $2.5 \%$ price savings realized by buyers who requested a quote through Autobytel.
} 
Baye, M. R. and J. Morgan (2001) "Information Gatekeepers on the Internet and the Competitiveness of Homogeneous Product Markets," American Economic Review, 91: 454-474.

Baye, M. R. and J. Morgan (2002) "Information Gatekeepers and Price Discrimination on the Internet," Economics Letters, 76: 47-51.

Baye, M. R., J. Morgan and P. Scholten (2006) "Persistent Price Dispersion in Online Markets," in D. W. Jansen (ed.), The New Economy and Beyond: Past, Present and Future, Edward Elgar: Cheltenham, U.K

Bester, H. (1994) "Price Commitment in Search Markets," Journal of Economic Behavior and Organization, 25; 109-120.

Biglaiser, G. (1993) “Middlemen as Experts,” Rand Journal of Economics, 24: 212-223.

Brynjolfsson, E. and M.D. Smith (2000) "Frictionless Commerce? A Comparison of Internet and Conventional Retailers," Management Science, 46: 563-585.

Brynjolfsson, E. and M.D. Smith (2001) "Customer Decision Making at an Internet Shopbot: Brand Still Matters," The Journal of Industrial Economics, 49: 541-558.

Chen, Y., G. Iyer and V. Padmanabhan (2002) "Referral Infomediaries," Marketing Science, 21: 412-434.

Clay K., R. Krishnan, and E. Wolff (2001) "Prices and Price Dispersion on the Web: Evidence from the Online Book Industry," Journal of Industrial Economics, 49: 521-539.

Ding, M., J. Eliashberg, J. Huber, and R. Saini (2005) "Emotional Bidders - An Analytical and Experimental Examination of Consumers' Behavior in a Priceline-Like Reverse Auction," Management Science, 51: 352-364.

Fay, S. (2004) "Partial-Repeat-Bidding in the Name-Your-Own-Price Channel," Marketing Science, 23: 407-418.

Ghose, A., T. Mukhopadhyay and U. Rajan (2002) "Strategic Benefits of Referral Services," Working Paper, Review of Marketing Science.

Larribeau, S., and T. Penard (2004) "Strategies and Price Competition on the Internet: Evidence from French Data," Working Paper, CREM, University of Rennes 1.

Scott Morton, F., F. Zettlemeyer and J. Silva Risso (2006) "The Role of the Internet in Lowering Prices: Evidence from Matched Survey and Auto Transaction Data," Forthcoming, Journal of Marketing Research.

Scott Morton, F., F. Zettlemeyer and J. Silva Risso (2004) "Cowboys or Cowards: Why Are Internet Car Prices Lower?” Working Paper, Yale School of Management. 
Scott Morton, F., F. Zettlemeyer and J. Silva Risso (2003) "Consumer Information and Discrimination: Does the Internet Affect the Pricing of New Cars to Women and Minorities?" Journal of Quantitative Marketing and Economics, 1: 77-92.

Scott Morton, F., F. Zettlemeyer and J. Silva Risso (2001) "Internet Car Retailing," Journal of Industrial Economics, 49: 501-519.

Spier, K. E. (1990) "Hagglers and Posters: The Coexistence of Flexible and Fixed Prices," Harvard Institute of Economic Research Discussion Paper No. 1517.

Varian, H. (1980) “A Model of Sales,” American Economic Review, 70: 651-659.

Viswanathan S., J. Kuruzovich, S. Gosain, and R. Agarwal (2005) "Online Infomediaries and Price Discrimination: Evidence from the Auto-retailing Sector," Working Paper, R.H. Smith School of Business, University of Maryland.

Wang, R. (1995) "Bargaining versus Posted Price Selling," American Economic Review, 89: $1747-1764$.

\section{$6 \quad$ Appendix}

Proof of Proposition 1. To determine whether firm $A$ should establish a referral price $r$ of $\gamma_{2} v$ or $\gamma_{1} v$, note that $R_{A}\left(\gamma_{2} v\right)>R_{A}\left(\gamma_{1} v\right)$ if

$$
-c / \tilde{\lambda}+\phi_{r} \gamma_{2} v+\phi_{n r} \overline{\mathcal{N}}>\frac{-c / \tilde{\lambda}+\phi_{r} \alpha \gamma_{1} v+\phi_{n r} \bar{\gamma}}{1-\phi_{r}(1-\alpha)}
$$

This condition can be restated as

$$
(1-\alpha) N c / \lambda>\delta \alpha v[\phi(N-2)+2-\alpha(1-\phi)]
$$

or

$$
\delta<\frac{(1-\alpha) N c / \lambda}{\alpha v[\phi(N-2)+2-\alpha(1-\phi)]} \equiv \hat{\delta}
$$

Proof of Proposition 4. Equations (2) and (3) imply that $R_{A}\left(\gamma_{2} v\right)-\widetilde{R}_{A}=\frac{N \phi((N-1) c / \lambda-\alpha v \delta)}{1+(N-1) \phi}$ which is greater than zero if $\phi \neq 0$ and $\delta<\frac{(N-1) c / \lambda}{\alpha \nu}$. Because firm $A$ sets $r=\gamma_{2} v$ if $\delta \leq \hat{\delta}$, if $\frac{(N-1) c / \lambda}{\alpha v}>\hat{\delta}$, then $\delta \leq \hat{\delta}$ 
implies $\delta<\frac{(N-1) c / \lambda}{\alpha v}$, and $S>0$ when $\delta \leq \hat{\delta} . \quad \frac{(N-1) c / \lambda}{\alpha v}>\hat{\delta} \quad$ holds if $(N-1)[\phi(N-2)+2-\alpha(1-\phi)]-(1-\alpha) N>0$. Thus, the fact that

$$
\begin{aligned}
& (N-1)[\phi(N-2)+2-\alpha(1-\phi)]-(1-\alpha) N \\
= & N[1-\phi(1-\alpha)]-2(1-\phi)+\alpha(1-\phi)+\phi N(N-2) \\
> & (N-2)(1-\phi)+\alpha(1-\phi)+\phi N(N-2)>0,
\end{aligned}
$$

where the first inequality follows from the fact that $N[1-\phi(1-\alpha)]>N(1-\phi)$, verifies that $S>0$ when $\delta \leq \hat{\delta}$.

Equations (1) and (3) imply that $R_{A}\left(\gamma_{1} v\right)-\widetilde{R}_{A}=\frac{N \phi[(\alpha N-1) c / \lambda+(1-\alpha) \alpha \delta v]}{1-\phi+\alpha N \phi}$ which is greater than zero if $\delta>\frac{(1-\alpha N) c / \lambda}{(1-\alpha) \alpha v}$. Because firm $A$ sets $r=\gamma_{1} v$ if $\delta>\hat{\delta}$, if $\frac{(1-\alpha N) c / \lambda}{(1-\alpha) \alpha v}<\hat{\delta}$, then $\delta>\hat{\delta}$ implies $\delta>\frac{(1-\alpha N) c / \lambda}{(1-\alpha) \alpha v}$, and $S>0$ when $\delta>\hat{\delta}$. Because $\hat{\delta}>0, \frac{(1-\alpha N) c / \lambda}{(1-\alpha) \alpha v}<\hat{\delta}$ is always satisfied if $\alpha \geq 1 / N . \hat{\delta}>\frac{(1-\alpha N) c / \lambda}{(1-\alpha) \alpha v}$ holds if

$$
(1-\alpha)^{2} N>(1-\alpha N)[\phi(N-2)+2-\alpha(1-\phi)]
$$

Because both sides of equation (9) are strictly decreasing in $\alpha$, and because the inequality is satisfied at both $\alpha=0$ and $\alpha=1 / N$, equation (9) is satisfied for all $\alpha \in[0,1 / N]$. Thus, $\delta>\hat{\delta}$ implies $\delta>\frac{(1-\alpha N) c / \lambda}{(1-\alpha) \alpha v}$ which verifies that $S>0$ when $\delta>\hat{\delta}$.

The comparative statics results follow from differentiation of the relevant expressions for $S$.

Proof of Lemma 5. Suppose $p_{A} \geq((N-1) c / \lambda) / \gamma_{2} \equiv \hat{p}$, so the numerator of $\widetilde{p}_{n} \equiv \frac{(1-\alpha)\left[(N-1) c / \lambda-\gamma_{2} v\right]}{\alpha N \gamma_{1}-[1+\alpha(N-1)] \gamma_{2}}$ is negative. The denominator can be either positive or negative. If

$$
\frac{\gamma_{2}}{\gamma_{1}}<\frac{\alpha N}{1+\alpha(N-1)}
$$

so that the denominator of $\widetilde{p}_{n}$ is positive, then $\widetilde{p}_{n} \leq 0$. Thus, because condition (6) is satisfied if $p_{n} \geq \widetilde{p}_{n}$, we have $R_{A}\left(p_{A}, \gamma_{1} p_{n}\right) \geq R_{A}\left(p_{A}, \gamma_{2} p_{n}\right)$ if and only if $p_{n} \geq \widetilde{p}_{n}$. Thus, $r=\gamma_{1} p_{n}$ for all $p_{n} \geq 0$. If 


$$
\frac{\gamma_{2}}{\gamma_{1}}>\frac{\alpha N}{1+\alpha(N-1)}
$$

so that the denominator of $\widetilde{p}_{n}$ is negative, then $\widetilde{p}_{n}>0$, and $R_{A}\left(p_{A}, \gamma_{1} p_{n}\right) \geq R_{A}\left(p_{A}, \gamma_{2} p_{n}\right)$ if and only if $p_{n} \leq \widetilde{p}_{n}$. Thus, $r=\gamma_{1} p_{n}$ if $p_{n} \leq \widetilde{p}_{n}$, and $r=\gamma_{2} p_{n}$ if $p_{n}>\widetilde{p}_{n}$.

Now suppose $p_{A}<\hat{p}$ so the numerator of $\tilde{p}_{n} \equiv \frac{(1-\alpha)\left[(N-1) c / \lambda-\gamma_{2} v\right]}{\alpha N \gamma_{1}-[1+\alpha(N-1)] \gamma_{2}}$ is strictly positive. If (10) holds so that the denominator of $\widetilde{p}_{n}$ is positive, then $\widetilde{p}_{n}>0$, and $R_{A}\left(p_{A}, \gamma_{1} p_{n}\right) \geq R_{A}\left(p_{A}, \gamma_{2} p_{n}\right)$ if and only if $p_{n} \geq \widetilde{p}_{n}$. Thus, $r=\gamma_{1} p_{n}$ if $p_{n} \geq \widetilde{p}_{n}$, and $r=\gamma_{2} p_{n}$ if $p_{n}<\widetilde{p}_{n}$.

If equation (11) holds so that the denominator of $\widetilde{p}_{n}$ is negative, then $\widetilde{p}_{n}<0$, and $R_{A}\left(p_{A}, \gamma_{1} p_{n}\right) \geq R_{A}\left(p_{A}, \gamma_{2} p_{n}\right)$ if and only if $p_{n} \leq \widetilde{p}_{n}$. Thus, $r=\gamma_{2} p_{n}$ for any value of $p_{n} \geq 0$.

Proof of Lemma 6. Firm $A$ 's ability to establish a high advertised price is limited by the referral price $r$. If $p_{A}>\frac{\gamma_{1}}{\gamma_{2}} p_{n}$, then because lemma 5 implies $r \leq \gamma_{1} p_{n}$, all buyers would prefer the referral price $r$ over bargaining (which would result in a price of $\gamma_{2} p_{A}>r$ for a good bargainer), so $p_{A}$ cannot exceed $\frac{\gamma_{1}}{\gamma_{2}} p_{n}$. In addition, by assumption, the advertised price cannot exceed $v$. Therefore, the advertised price $p_{A}$ must satisfy $p_{A}=\min \left\{v, \frac{\gamma_{1}}{\gamma_{2}} p_{n}\right\}$

Proof of Proposition 7. First, suppose that $\frac{\gamma_{2}}{\gamma_{1}} \leq \Delta$. Recall from lemma 5 that if $\gamma_{2} / \gamma_{1} \leq \Delta$ (buyers' bargaining abilities are strongly heterogeneous), then firm $A$ will set $r=\gamma_{1} p_{n}$ if $p_{A}>((N-1) c / \lambda) / \gamma_{2} \equiv \hat{p}$. Because this results in the non-referred firms selling to all good bargainers, equation (8) implies that each non-referred firm's return is strictly increasing in $p_{n}$, so non-referred firms will set $p_{n}=v$. If $\gamma_{2} / \gamma_{1} \leq \Delta$ and $p_{A}<\hat{p}$, then lemma 5 implies that non-referred firms can only induce firm $A$ to concede good bargainers if $p_{n} \geq \widetilde{p}_{n}$, so it is optimal for the non-referred firms to advertise the highest possible price, $p_{n}=v$. Firm $A$ will respond by setting $p_{A}=v$. Substituting $p_{A}=v$ in equation (7) yields $\tilde{p}_{n}=\frac{(1-\alpha)\left[(N-1) c / \lambda-\gamma_{2} v\right]}{\alpha N \gamma_{1}-[1+\alpha(N-1)] \gamma_{2}}$. If $\widetilde{p}_{n} \leq v$, which simplifies to $v \geq \frac{(1-\alpha)(N-1) c / \lambda}{\alpha N v\left(\gamma_{1}-\gamma_{2}\right)}$, then lemma 5 implies that firm $A$ will set set $r=\gamma_{1} p_{n}=\gamma_{1} v$. However, if $v<\frac{(1-\alpha)(N-1) c / \lambda}{\alpha N v\left(\gamma_{1}-\gamma_{2}\right)}$, then firm $A$ will set $r=\gamma_{2} v$ and capture all buyers through the referral system. 
Next, suppose $\frac{\gamma_{2}}{\gamma_{1}}>\Delta$ and $v \geq \hat{p}$. In this case, $R_{A}\left(p_{A}, \gamma_{1} p_{n}\right) \geq R_{A}\left(p_{A}, \gamma_{2} p_{n}\right)$ if $p_{n} \leq \widetilde{p}_{n}$. If firm $A$ chooses an advertised price $p_{A} \leq \hat{p}$, then $\widetilde{p}_{n} \leq 0$, so $p_{n}>\widetilde{p}_{n}$. Thus, firm $A$ will set $r=\gamma_{2} p_{n}$ and capture all buyers through the referral system, and will earn a return of $R_{A}\left(p_{A}, \gamma_{2} p_{n}\right)=-c / \lambda+\gamma_{2} p_{n}$. If firm $A$ sets $p_{A} \geq \hat{p}$, then $\widetilde{p}_{n} \geq 0$, and nonreferred firms will set $p_{n}=\min \left\{\widetilde{p}_{n}, v\right\}$ (so $p_{n} \leq \widetilde{p}_{n}$ ) in order to induce firm $A$ to concede the good bargainers. Assuming non-referred firms set $p_{n}=\widetilde{p}_{n}$, firm $A$ 's return is maximized when $\widetilde{p}_{n}$ is as large as possible. Because $\widetilde{p}_{n}$ is an increasing function of $p_{A}$ when $\frac{\gamma_{2}}{\gamma_{1}}>\Delta$ and $p_{A} \geq \hat{p}$, firm $A$ would like to set the highest advertised price possible which implies $p_{A}=\min \left\{v, \frac{\gamma_{1}}{\gamma_{2}} \widetilde{p}_{n}\right\}$. Substituting $p_{A}=\frac{\gamma_{1}}{\gamma_{2}} \widetilde{p}_{n}$ into equation (7) and solving for $\widetilde{p}_{n}$ yields $\widetilde{p}_{n}=\frac{(1-\alpha)(N-1) c / \lambda}{\left(\gamma_{1}-\gamma_{2}\right)(1+\alpha(N-1))}$. Thus, if firm $A$ chooses to advertise $p_{A} \geq \hat{p}$, then the optimal advertised price is $p_{A}=\min \left\{v, \frac{\gamma_{1}}{\gamma_{2}} \frac{(1-\alpha)(N-1) c / \lambda}{\left(\gamma_{1}-\gamma_{2}\right)(1+\alpha(N-1))}\right\}$, and the optimal referral price is $r=\gamma_{1} p_{n}$. Finally, to see that firm $A$ prefers to advertise $p_{A} \geq \hat{p}$ if $v \geq \frac{(1-\alpha)(N-1) c / \lambda}{\left(\gamma_{1}-\gamma_{2}\right)(1+\alpha(N-1))}$, note that for any price $\widetilde{p}_{n}$ advertised by the non-referred firms, equations (4) and (5) imply that firm $A$ 's return from setting $r=\gamma_{1} \widetilde{p}_{n}$ and $p_{A}=\frac{\gamma_{1}}{\gamma_{2}} \widetilde{p}_{n}$ is greater than or equal to the return from setting $r=\gamma_{2} \widetilde{p}_{n}$ if

$$
\frac{-N c / \lambda+\alpha N \gamma_{1} \widetilde{p}_{n}+(1-\alpha) \gamma_{1} \widetilde{p}_{n}}{1+\alpha(N-1)} \geq-c / \lambda+\gamma_{2} \widetilde{p}_{n}
$$

or $\tilde{p}_{n} \geq \frac{(1-\alpha)(N-1) c / \lambda}{\left(\gamma_{1}-\gamma_{2}\right)(1+\alpha(N-1))}$ which holds if $v \geq \frac{(1-\alpha)(N-1) c / \lambda}{\left(\gamma_{1}-\gamma_{2}\right)(1+\alpha(N-1))}$. However, if $v<\frac{(1-\alpha)(N-1) c / \lambda}{\left(\gamma_{1}-\gamma_{2}\right)(1+\alpha(N-1))}$, then for any price $p_{n}$ advertised by the non-referred firms, it will be optimal for firm $A$ to set $r=\gamma_{2} p_{n}$ to capture all buyers through the referral system.

Finally, suppose $\frac{\gamma_{2}}{\gamma_{1}}>\Delta$ and $\hat{p}>v$. Because lemma 6 implies $p_{A} \leq v$, firm $A$ is forced to set $p_{A}<\hat{p}$, and lemma 5 implies $r=\gamma_{2} p_{n}$. The non-referred firms make no sales and have no single optimal pricing strategy. Any price $p_{n} \in\left((c / \lambda) / \gamma_{2}, v\right]$ that does not exceed $v$ and yields a positive return for firm $A$ is possible. Furthermore, firm $A$ cannot 
increase its profit by advertising a price $p_{A}<p_{n}$, any price $p_{A} \in\left[p_{n}, \min \left\{v, \frac{\gamma_{1}}{\gamma_{2}} p_{n}\right\}\right]$ results in all buyers purchasing through the referral system.

Proof of Proposition 8. In the absence of the referral system, the average market price is $\bar{\gamma}$. From proposition 7, if $\frac{\gamma_{2}}{\gamma_{1}} \leq \Delta$ and $v \geq \frac{(1-\alpha)(N-1) c / \lambda}{\alpha N\left(\gamma_{1}-\gamma_{2}\right)}$, then $p_{A}=v$ and $r=\gamma_{1} v$, and the average market price is $\bar{\gamma}$. If $\frac{\gamma_{2}}{\gamma_{1}}>\Delta$ and $v>\max \left\{((N-1) c / \lambda) / \gamma_{2}, \frac{(1-\alpha)(N-1) c / \lambda}{\left(\gamma_{1}-\gamma_{2}\right)(1+\alpha(N-1))}\right\}, \quad$ then $\quad$ proposition $\quad 7 \quad$ implies $p_{n}=\frac{(1-\alpha)(N-1) c / \lambda}{\left(\gamma_{1}-\gamma_{2}\right)(1+\alpha(N-1))}<v$, weak bargainers purchase through the referral system at a price $r=\gamma_{1} p_{n}<\gamma_{1} v$, and good bargainers purchase from non-referred dealers at a price $\gamma_{2} p_{n}$. The average market price is $\bar{\gamma}_{n}<\bar{\gamma}$, but weak bargainers pay $\gamma_{1} p_{n}>\bar{\gamma}_{n}$. For all other ranges of $v$ and $\gamma_{2} / \gamma_{1}$ proposition 7 implies all buyers purchase from firm $A$ at the price $r=\gamma_{2} v$.

Proof of Proposition 9. The results follow from the fact that if $\frac{\gamma_{2}}{\gamma_{1}} \leq \Delta$ and $v \geq \frac{(1-\alpha)(N-1) c / \lambda}{\alpha N\left(\gamma_{1}-\gamma_{2}\right)}$, then proposition 7 implies $p_{A}=v$ and $r=\gamma_{1} v$, so

$$
\begin{aligned}
S & =R_{A}\left(v, \gamma_{1} v\right)-\widetilde{R}_{A}=\frac{-c / \lambda+\alpha \gamma_{1} v+(1-\alpha) \gamma_{2} v / N}{1+\alpha(N-1) / N}-(-N c / \lambda+\bar{\gamma}) \\
& =\frac{\alpha(N-1)\left(v\left(\gamma_{1}-\bar{\gamma}\right)+c / \lambda\right)}{1+\alpha(N-1)}>0 .
\end{aligned}
$$

The comparative statics results follow from differentiation of this expression for $S$.

Similarly, if $\frac{\gamma_{2}}{\gamma_{1}} \leq \Delta$ and $\quad v<\frac{(1-\alpha)(N-1) c / \lambda}{\alpha N\left(\gamma_{1}-\gamma_{2}\right)} \quad$ or $\quad$ if $\quad \frac{\gamma_{2}}{\gamma_{1}}>\Delta \quad$ and $\frac{(1-\alpha)(N-1) c / \lambda}{\left(\gamma_{1}-\gamma_{2}\right)(1+\alpha(N-1))}>v \geq((N-1) c / \lambda) / \gamma_{2}$, then proposition 7 implies $r=\gamma_{2} v$ so

$$
\begin{aligned}
S & =R_{A}\left(v, \gamma_{2} v\right)-\widetilde{R}_{A}=-C / \lambda+\gamma_{2} v-(-N C / \lambda+\bar{\gamma}) \\
& =(N-1) c / \lambda-\alpha\left(\gamma_{1}-\gamma_{2}\right) v
\end{aligned}
$$


which is positive if $v<(N-1) c / \lambda /\left(\alpha\left(\gamma_{1}-\gamma_{2}\right)\right)$ which always holds because the restrictions on $v$ imply $v<\frac{(1-\alpha)(N-1) c / \lambda}{\alpha N\left(\gamma_{1}-\gamma_{2}\right)}$. Again, comparative statics results follow directly from differentiation of the expression for $S$.

Suppose $\quad \frac{\gamma_{2}}{\gamma_{1}}>\Delta \quad$ and $\quad v \geq \max \left\{\frac{(1-\alpha)(N-1) c / \lambda}{\left(\gamma_{1}-\gamma_{2}\right)(1+\alpha(N-1))},((N-1) c / \lambda) / \gamma_{2}\right\} . \quad$ Then proposition 7 implies that $p_{n}=\frac{(1-\alpha)(N-1) c / \lambda}{\left(\gamma_{1}-\gamma_{2}\right)(1+\alpha(N-1))}$ and $p_{A}=\frac{\gamma_{1}}{\gamma_{2}} p_{n}$. Substituting $p_{A}=\frac{\gamma_{1}}{\gamma_{2}} p_{n}$ into $S=R_{A}\left(p_{A}, \gamma_{1} p_{n}\right)-\widetilde{R}_{A}$ yields $S=\frac{p_{n} \gamma_{1}(1+\alpha(N-1))+\alpha N(N-1) c / \lambda}{1+\alpha(N-1)}-\overline{\mathcal{N}}$ which is positive if and only if

$$
p_{n}>\frac{-\alpha N(N-1) c / \lambda}{\gamma_{1}(1+\alpha(N-1))}+\frac{\bar{\gamma}}{\gamma_{1}}
$$

Substituting $p_{n}=\frac{(1-\alpha)(N-1) c / \lambda}{\left(\gamma_{1}-\gamma_{2}\right)(1+\alpha(N-1))}$ and simplifying, this expression can be restated as

$$
v<\frac{(N-1) c / \lambda}{\bar{\gamma}(1+\alpha(N-1))} \frac{(1-\alpha) \gamma_{1}+\alpha N\left(\gamma_{1}-\gamma_{2}\right)}{\gamma_{1}-\gamma_{2}} .
$$

